\title{
BMJ Open Trajectories of sickness absence after road traffic injury: a Swedish register- based cohort study
}

\author{
Ritva Rissanen, ${ }^{1}$ Yajun Liang, ${ }^{1}$ Jette Moeller, ${ }^{1}$ Alicia Nevriana, ${ }^{1}$ Hans-Yngve Berg, ${ }^{1,2}$ \\ Marie Hasselberg ${ }^{1}$
}

To cite: Rissanen R, Liang $\mathrm{Y}$, Moeller J, et al. Trajectories of sickness absence after road traffic injury: a Swedish registerbased cohort study. BMJ Open 2019;9:e031132. doi:10.1136/ bmjopen-2019-031132

- Prepublication history and additional material for this paper are available online. To view please visit the journal online (http://dx.doi.org/10.1136/ bmjopen-2019-031132).

Received 18 April 2019 Revised 08 July 2019 Accepted 10 July 2019

Check for updates

(C) Author(s) (or their employer(s)) 2019. Re-use permitted under CC BY-NC. No commercial re-use. See rights and permissions. Published by BMJ.

${ }^{1}$ Department of Public Health Sciences, Karolinska Institute, Stockholm, Sweden

${ }^{2}$ Swedish Transport Agency, Borlänge, Sweden

Correspondence to Dr Ritva Rissanen; ritva.rissanen@ki.se

\section{ABSTRACT}

Objectives Despite much focus on the health impact of road traffic injury (RTI) on life, there is a lack of knowledge of the dynamic process of return to work following RTI and its related factors. The aim of this study was to identify longitudinal patterns of sickness absence (SA) following RTI, to examine the patterns' interplay with health-related quality of life (HRQLL) and to determine if there are differences, regarding the patterns and interplay, according to injury severity.

Design A register-based prospective cohort study. Setting Administrative data on RTI in Sweden from the Swedish Traffic Accident Data Acquisition System (STRADA) and Swedish Social Insurance data.

Participants Individuals suffering an RTI (total $n=4761$ ) were identified in STRADA between 1 January 2007 and 31 December 2009. A total of 903 of these met the inclusion criteria for the current study and were included. Primary and secondary outcome measures The primary outcome measure was SA following RTI. The secondary outcome measure was HRQOL.

Results Three distinct patterns of SA were identified 'Stable', 'Quick decrease' and 'Gradual decrease'. The patterns differed in the number of initial SA days and the rate of reduction of SA days. After 3 years, all three patterns had almost the same level of SA. Higher injury severity and a higher number of $S A$ days had a negative interplay with HRQoL. Participants who initially had a higher number of SA days were more likely to report a low HRQoL, indicating that people with a slower return to work are more vulnerable. Conclusion The study highlights the heterogeneity of return to work after an RTI. People with a more severe injury and slower pace of return to work seem to be more vulnerable with regards to HRQoL loss following RTI.

\section{INTRODUCTION}

Despite much focus on the impact of road traffic injury (RTI) on life, ${ }^{12}$ there is still lack of knowledge on the dynamic process and factors associated with return to work following RTI. There is agreement between researchers, medical professions, governments and businesses that, in general, work is good for health and well-being. ${ }^{34}$ A delayed return to work has been identified as a risk factor for further decrease of health, and return to work can be viewed as an indicator

\section{Strengths and limitations of this study}

This study offers a unique combination of data collection modes, where health-related quality of life (HRQoL) was collected by a self-reported questionnaire and sickness absence $(\mathrm{SA})$ and injury data were retrieved from national high-quality registers containing social insurance data for all residents in Sweden.

- By using register-based data this study is able to capture the dynamic patterns of SA following road traffic injury.

- One of the limitations of this study is that we were not able to assess HRQoL over several time points; hence, we cannot draw conclusions on the change of HRQoL over the study period.

for real life functioning. ${ }^{5}$ Studies have identified a varying rate of individuals who report sickness absence (SA) or have a delayed or failed return to work following RTI, that is, a resumption of SA after a return to work, (ranging from $14 \%$ to $42 \%$ ). ${ }^{6-9}$ Persons who have a greater number of SA days and have a delayed or failed return to work report significantly lower self-reported health compared with their counterparts. ${ }^{10-13}$

Currently, there is no consensus on the definition of return to work, ${ }^{5}$ and it has been operationalised in multiple ways as an outcome in research. So far, return to work has predominantly been assessed by a dichotomised outcome during a specific follow-up period. This method has been used both regarding self-reported data collections via questionnaires and data retrieved from administrative records. Self-administrated questionnaires have mainly been used to study return to work by asking the person to indicate whether or not they have returned to work, ${ }^{814}$ not considering the variation return to work might entail that is, part-time or full time and type of work position. The data derived from administrative records vary in quality and are most often derived from information pertaining to 
compensation claims or wage replacement benefits (eg, sickness benefits) ${ }^{69}$ These methodologies result in limitations regarding return to work as an outcome. First, we need to consider the dynamic process of SA. SA following RTI may vary over time, and cross-sectional methods will not capture this variation. Second, the dynamic process implies that the predictors of SA may also vary over time due to the changeability of the causes of the SA. The causes of SA might therefore differ depending on when, in time, $\mathrm{SA}$ is measured.$^{15}$ It is plausible that reasons for SA in close proximity to the injury event, are more governed by the physical injuries rather than the psychological processes triggered by the injury event. Psychological processes might instead be more prominent as time goes on and the physical injuries heal. ${ }^{1617}$ Hence, study results vary depending on the definition and assessment of return to work, time frame for the follow-up, severity of the injury and contextual factors such as compensation schemes and healthcare and social insurance systems.

Several cohort studies have investigated factors influencing failed return to work. These studies have identified injury-related factors such as injury severity, disability level and injury type as predictors, ${ }^{1018-22}$ with more severe injuries reporting a higher number of SA days following the injury ${ }^{18}$ and a slower return to work (56\% slower) ${ }^{20}$ compared with those suffering mild injuries. For example, Hours and colleagues ${ }^{18}$ found that $32 \%$ of those suffering severe injuries had not returned to work 1 year after the injury event, compared with $5 \%$ of those with mild injuries. Regarding injury type, for example, lower extremity injury has been associated with a slower rate of return to work $\left(69 \%\right.$ slower) compared with other injuries. ${ }^{20}$ Other factors that have been associated with failed returning to work include intention to press charges, ${ }^{23}$ long hospital stay, ${ }^{7}$ low expectations of return to work, ${ }^{10}$ occupational status, ${ }^{2021}$ chronic pain ${ }^{1123}$ and post-traumatic stress disorder. $^{11}$

Considering the lack of knowledge and evidence of the dynamic patterns and factors associated with SA and return to work following RTI, more research addressing these issues is warranted. ${ }^{5}$ By identifying individuals with similar patterns of return to work and factors associated with these patterns, it will be possible to have greater accuracy in early identification of people that are at risk of longterm or recurrent SA and also with regard to the need for early support and interventions. Consequently, the primary objective of this study was to identify longitudinal patterns of SA following RTI, with a secondary objective to examine the patterns' interplay with health-related quality of life (HRQoL) as well as to determine if there are differences, regarding both the patterns and the interplay, according to injury severity. For the primary objective SA is considered as an outcome, while SA acts as an independent variable for the secondary objective where HRQoL is the outcome. We hypothesise that there will be distinct trajectories of SA after RTI with a variation regarding injury severity and sociodemographic characteristics. Furthermore, HRQoL is expected to vary between trajectories.

\section{METHODS}

\section{Data collection and population}

The current study is a part of the Swedish project, 'QoL following RTI,,${ }^{24}$ in which retrospective data were collected from both self-reported and administrative sources, that is, register data. Individuals suffering an RTI (total $\mathrm{n}=4761$ ) were identified in the Swedish Traffic Accident Data Acquisition System (STRADA) between 1 January 2007 and 31 December 2009 (procedure described in detail elsewhere) ${ }^{24}$ Self-reported data on HRQoL were collected via a short survey sent out via regular mail in November 2010, and injury data were collected from STRADA. A total of 1797 persons completed the EuroQoL five dimention scale (EQ5D) and returned the questionnaire (including children and people over the age of 64 years). In the original study 'QoL following RTI', ${ }^{24}$ a comparison of the respondents and the non-respondents was conducted. There were some differences between those who responded and those who did not. There were significantly more women $(\mathrm{p}<0.01)$ among the respondents compared with the non-respondents, especially among the middle-aged and elderly respondents (elderly not included in the current study).

The current study included participants aged between 19 years and 64 years, that is, a working age population in Sweden. The upper age limit of 64 years was set as the Swedish social insurance system is, in most cases, only available until the age of 65 years as this is the age of retirement in Sweden. ${ }^{25}$ The total number of participants in the current study was 903, due to inclusion criteria. The inclusion criteria in the current study was: an RTI between the years of 2007 and 2009, and age between 19 years and 64 years. Exclusion was RTI due to falls and incomplete HRQoL assessment (see flow chart in online supplementary figure 1 for details). The average age of the participants was 42.2 years (SD 13.7), and a majority of the sample was men $(53.2 \%)$.

In the current study, additional data on SA were retrieved from the Micro Data for Analysis of Social Insurance (MiDAS) and the Longitudinal Integration Database for Health Insurance and Labour Market Studies (LISA). MiDAS registry is managed by the Swedish Social Insurance Agency and contains information on social insurance for all Swedish residents since 1992. ${ }^{26}$ LISA contains employment data and is managed by Statistics Sweden. ${ }^{27}$

\section{Sickness absence}

As an inherent part of the Swedish welfare system, financial security by the social insurance system is offered to individuals in times of work incapacity. ${ }^{28}$ During the first 14 days of SA, compensation to the individual is provided by the employer of those employed (employer-paid sick leave), with the exception of a waiting period when no employer-paid sick leave is offered (usually the first day of a SA spell). If the SA is prolonged for more than 14 days, the Swedish Social Insurance Agency is responsible for a sickness benefit corresponding to about $80 \%$ of the individual's salary. ${ }^{29}$ 
Information regarding SA (including number of days, extent and number of spells), both for 3 years prior and 3 years' postinjury was used. SA was operationalised as the mean number of gross SA days divided into 180-day periods for the follow-up of 3 years. Data were retrieved from two registers: MiDAS and LISA.

\section{Injury severity}

Data on injury severity and injured body part were retrieved from STRADA, which is a national registry including road traffic crashes reported by the police and emergency care hospitals in Sweden. ${ }^{30}$ In STRADA, injury severity is recorded based on the Abbreviated Injury Scale (AIS), ${ }^{31}$ which contains the component on injured body region (head, face, neck, thorax, abdomen, spine, upper extremity, lower extremity and unspecified), as well as the severity itself ( $1=$ minor, $2=$ moderate, $3=$ serious, $4=$ severe, $5=$ critical, $6=$ maximal). If someone is injured at multiple body regions, we only took into account the most severe injury and the value is recorded as Maximum AIS (MAIS).${ }^{32}$ We then categorised MAIS into $1=$ minor, $2=$ moderate and $3+=$ severe. Out of the 903 participants, 205 suffered injuries classified as severe injuries, that is, MAIS $3+(22.7 \%)$.

\section{Overall HRQoL}

QoL refers to an individual's satisfaction and well-being in life and has been defined by the WHO QoL Group as following: 'An individual's perception of their position in life in the context of the culture and value system in which they live and in relation to their goals, expectations, standards and concerns' ${ }^{33}$ QoL is a multidimensional construct, hence a more narrow concept of HRQoL has been developed to include only those aspects that are related to health. ${ }^{34}$ In the current study the EQ5D ${ }^{35}$ was included for the assessment of HRQoL. EQ5D is a standardised measure of self-rated health, which assesses QoL in five dimensions: mobility, self-care, usual activities, pain/discomfort and anxiety/depression. Each dimension has three levels: no problems, some problems and extreme problems. A single summary index can be retrieved by applying a weight to each of the levels in each dimension. The range of the summary index is from 0 to 1 , where 0 is a health status equal to dead and 1 indicates full health. EQ5D has been validated in several different settings and populations, including different injury populations, showing robust psychometric properties. ${ }^{36-38}$

\section{Statistical analysis}

The patterns of SA days were assessed by using the groupbased trajectory model (GBTM), ${ }^{39}{ }^{40}$ which assigned every participant to a class-specific trajectory. ${ }^{39}$ Values of Bayesian Information Criterion (BIC), group membership and posterior class membership probability were used to identify the exact number of trajectories and the best fit model. ${ }^{40} \mathrm{BIC}$ was recorded for each model, and the lowest BIC value was used to find the optimal number of classes or trajectories. A group membership indicates the number of participants in a given trajectory. The values of the average posterior probabilities of group membership in the modelled trajectories pools individuals with similar patterns of change and discriminates between individuals with dissimilar patterns of change. ${ }^{40}$

In this study, the zero inflated Poisson model was used for GBTM due to the skewed distribution of SA days. In GBTM, time was considered as the independent variable, SA as the dependent variable and MAIS as the covariate. Because the change of SA days might have a non-linear pattern, we included three terms of time since the injury, that is, linear, quadratic and cubic, to observe the change in either magnitude or direction across time points. Different trajectory groups were assigned to GBTM, and the one with lower BIC and higher posterior class membership probability was presented as the final pattern. GBTM showed that three patterns were found with the best model fit, that is, lower BIC and higher posterior class membership probabilities. The model parameters and mean posterior class membership probabilities (ie, the probability that a person belongs to a certain class) are shown in online supplementary table 1.

After trajectory analysis, analysis of variance and $\chi^{2}$ tests were used to compare the characteristics among three trajectory groups for continuous variables and categorical variables, respectively. After the comparison of HRQoL by the $\chi^{2}$ tests, binary logistic regression was performed to assess the association between SA trajectory and HRQoL. Two models were computed; a crude model and a model where we adjusted for age, sex, education and sick leave days 1 year prior to injury. OR and $95 \%$ CI were used to describe the associations after adjusting for sociodemographic factors, MAIS and number of SA days prior to injury. Stratified analysis by MAIS was done for both the trajectory identification and the association between trajectory and HRQoL.

All analyses were performed using IBM SPSS V.25 for Windows (IBM SPSS, Chicago, Illinois, USA) and SAS V.9.4 (SAS Institute, Cary, North Carolina, USA).

\section{Patient and public involvement}

Patients and the public were not involved in the design or planning of the study.

\section{Ethical consideration}

All participants gave informed consent for inclusion to the STRADA register and signed a consent form at the time of inclusion to the study.

\section{RESULTS}

\section{Trajectories for SA, total population}

The three patterns of SA days during the 3 years after injury are shown in figure 1 . Pattern 1 shows a 'Stable' pattern of SA days, with the lowest number of SA days during the first 6 months after the injury (including $76 \%$ of participants). Although the 'Stable' pattern had the lowest mean number of SA days during the first 6 months of the follow-up period, during the last 6 months, all three 


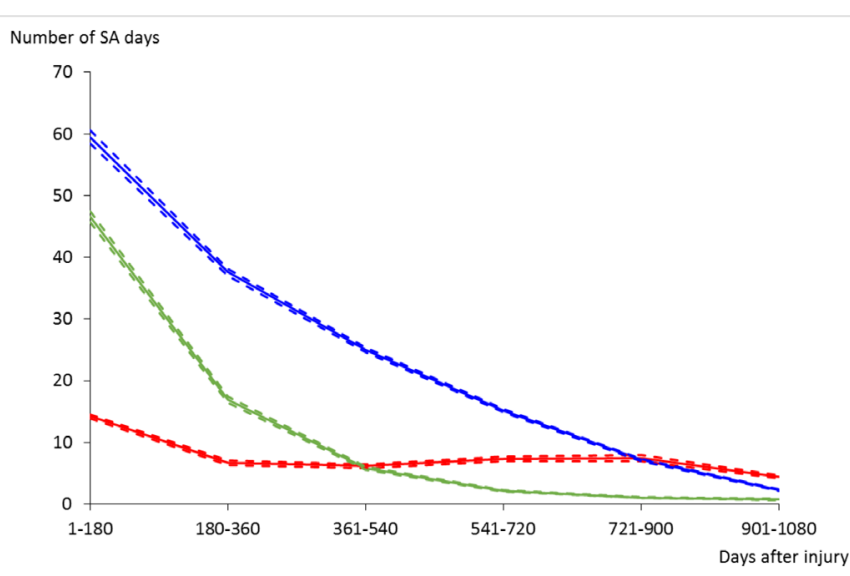

Figure 1 Trajectories for sickness absence (SA) for the 3 years after injury (total population) after adjusting for Maximum Abbreviated Injury Scale (MAIS) $(n=903)$. Solid lines indicate the actual trajectories, and dashed lines indicate the estimated 95\% Cls. Line 1 (red) represents the 'Stable' pattern, line 2 (green) represents the 'Quick decrease' pattern and line 3 (blue) represents the 'Gradual decrease' pattern.

patterns had almost the same mean number of SA days. Hence, pattern 1 presented a stable pattern over the study period with minor decrease in the mean number of SA days. Pattern 2 showed a 'Quick decrease' pattern of SA days, with a fast reduction of the mean number of SA days at the beginning of the follow-up and had the lowest mean number of SA days at the end of the study period (including $15 \%$ of participants). Pattern 3 represents a 'Gradual decrease' pattern of SA days (including 9\% of participants). The 'Gradual decrease' pattern displayed the highest mean number of SA days at the beginning of the study period, with a steady decline of SA days over the follow-up period, but showed a slower reduction regarding the mean number of SA days compared with the 'Quick decrease' pattern.

When we analysed the mean number of SA days prior to the injury for each identified pattern (data from MiDAS), the results showed that all three patterns displayed approximately the same mean number of SA days (10 compensated days) during the 3 years prior to the injury, hence there were no differences in the number of SA days prior to the injury between the trajectories. However, there was a slight increase in the mean number of SA days, from 10 compensated days to 20 compensated days, for the 'Gradual decrease' pattern during the 180 days prior to the injury, however this increase was not statistically significant $(p=0.769)$ (see online supplementary figure 2).

Table 1 shows the socioeconomic characteristics, injury severity and SA days of the participants across the three different patterns. There were no significant differences

Table 1 Characteristics of the participants in total and across different SA patterns $(n=903)$

\begin{tabular}{|c|c|c|c|c|c|}
\hline Characteristics & $\begin{array}{l}\text { Total } \\
(n=903)\end{array}$ & $\begin{array}{l}\text { 'Stable' } \\
(n=687)\end{array}$ & $\begin{array}{l}\text { 'Quick decrease' } \\
(\mathrm{n}=137)\end{array}$ & $\begin{array}{l}\text { 'Gradual decrease' } \\
(\mathrm{n}=79)\end{array}$ & $P$ values \\
\hline Age, years, mean (SD) & $42.4(13.7)$ & $41.9(13.9)$ & $42.7(13.4)$ & 46.7 (11.9) & 0.012 \\
\hline \multicolumn{6}{|l|}{ Education, n (\%) } \\
\hline University ( $\geq 13$ years) & $331(36.7)$ & $265(38.6)$ & $43(31.4)$ & $23(29.1)$ & 0.385 \\
\hline High school (10-12 years) & $466(51.6)$ & $343(49.9)$ & $75(54.7)$ & $48(60.8)$ & \\
\hline \multicolumn{6}{|l|}{ Occupation at the time of $\mathrm{RTI}{ }^{*}$} \\
\hline Senior officials and senior positions & $95(11.1)$ & $75(11.5)$ & $13(10.0)$ & $7(9.6)$ & $<0.001$ \\
\hline Qualified officials & $150(17.5)$ & $119(18.2)$ & $16(12.3)$ & $15(20.5)$ & \\
\hline Other officials & $95(11.1)$ & $74(11.3)$ & $13(10.0)$ & $8(11.0)$ & \\
\hline Vocational workers & $65(7.6)$ & $49(7.5)$ & $8(6.2)$ & $8(11.0)$ & \\
\hline Other workers & $125(14.6)$ & $74(11.3)$ & $39(30.0)$ & $12(16.4)$ & \\
\hline No employment & $158(18.5)$ & $142(21.7)$ & $13(10.0)$ & $3(4.1)$ & \\
\hline MAIS $(\geq 3), n(\%)$ & $205(22.7)$ & $108(15.7)$ & $59(43.1)$ & $38(48.1)$ & $<0.001$ \\
\hline $\begin{array}{l}\text { Number of SA days } 1 \text { year prior to injury, } \\
\text { mean (SD) }\end{array}$ & $10.1(46.4)$ & $6.8(34.2)$ & $14.7(61.3)$ & $31.3(86.3)$ & $<0.001$ \\
\hline
\end{tabular}

${ }^{*}$ There were 47 participants with missing values on occupation at RTI.

MAIS, Maximum Abbreviated Injury Scale; RTI, road traffic injury; SA, sickness absence. 


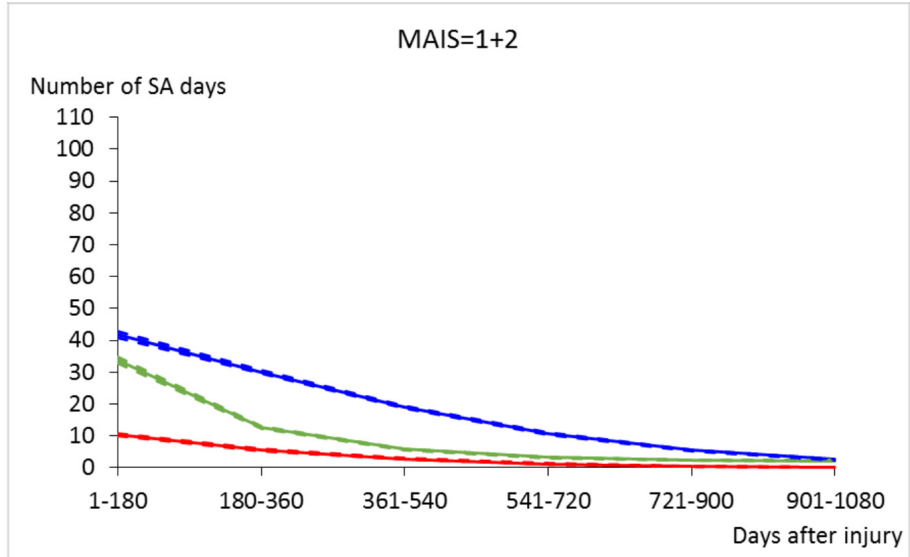

MAIS $\geq 3$

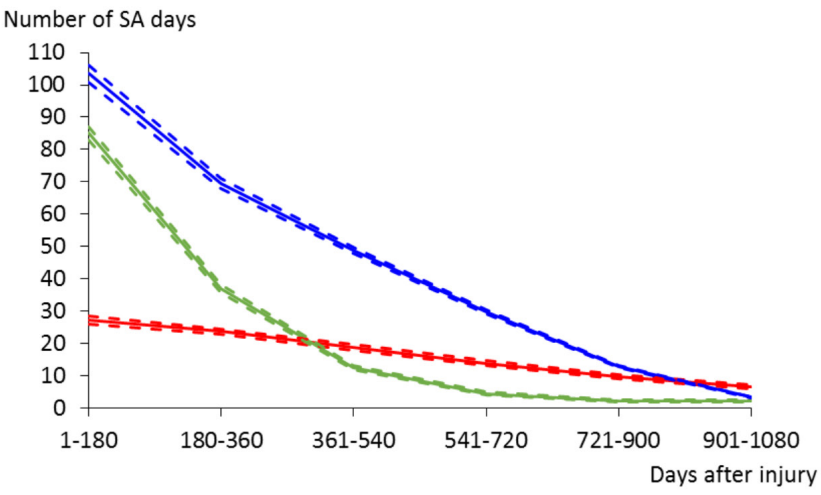

Figure 2 Trajectories for sickness absence (SA) for the 3 years after injury (stratified by the Maximum Abbreviated Injury Scale (MAIS)). Solid lines indicate the actual trajectories, and dashed lines indicate the estimated 95\% Cls. Line 1 (red) represents the 'Stable' pattern, line 2 (green) represents the 'Quick decrease' pattern and line 3 (blue) represents the 'Gradual decrease' pattern.

with regard to sex and education between the different patterns. The mean age was highest in the 'Gradual decrease' pattern $(\mathrm{p}=0.012)$. Moreover, there was a significant difference in the number of participants with an MAIS 3+ classified injury between the different patterns, with the highest proportion in the 'Gradual decrease' pattern. Participants in the 'Gradual decrease' pattern also had a significantly higher number of SA days during the year prior to the injury (see online supplementary figure 3 ).

\section{Patterns stratified by injury severity}

When the three patterns were stratified based on injury severity (MAIS 1 and 2 and MAIS $\geq 3$ ), they displayed patterns with slight differences. All three patterns for participants with more severe injuries (MAIS $\geq 3$ ) started on higher mean numbers of SA days (105, 85 and 29, for respective patterns, see figure 2) and had a steeper decrease compared with the patterns of participants with injuries classified as MAIS 1 and 2. Moreover, the 'Stable' pattern differed between the injury severities stratums. For participants with more severe injuries, the stable pattern showed a slower decrease over time than for participants with MAIS 1 and 2 injuries.

\section{Health-related quality of life}

There was a significant difference in reported HRQoL between the three patterns, both for overall HRQoL and for each construct (see table 2). When we analysed HRQoL stratified by MAIS, significant differences were detected for all domains except for problems in self-care and anxiety/depression for MAIS 3.

Table 3 shows how the patterns 'Quick decrease' and 'Gradual decrease' differ from the 'Stable' one, in terms of HRQoL, taking into account injury severity. For the total sample, participants with a 'Gradual decrease' and 'Quick decrease' in SA were more likely to report a significantly lower HRQoL (below median) compared with those with a 'Stable' pattern. The differences remained significant after adjustment for confounders (model 2). All HRQoL domains, except for self-care for those with a 'Quick decrease', were reported to be significantly more problematic for both groups compared with those with a 'Stable' pattern. The adjustment for confounders did not change these results.

Similar findings were present when considering participants with less severe injuries (MAIS 1 and 2). Participants with MAIS 1 and 2 classified injuries in the 'Gradual decrease' and 'Quick decrease' patterns were more likely to report an HRQoL below the median compared with participants with injuries classified in the the 'Stable' pattern. All of the HRQoL domains, except for the selfcare for the 'Quick decrease' pattern (crude and adjusted models) were found to be significantly more problematic for the 'Quick decrease' and the 'Gradual decrease' patterns compared with those with a 'Stable' pattern.

Contrary to the results of the less severe injuries, participants with a 'Quick decrease' pattern with MAIS 3 classified injuries (crude and adjusted models) did not have a significantly lower HRQoL compared with participants with a 'Stable' pattern. However, participants with a 'Quick decrease' pattern were more likely to report problems in usual activity and pain/discomfort compared with the 'Stable' pattern. The results did not change when adjusting for confounders. Participants with MAIS 3 classified injuries and with a 'Gradual decrease' pattern were more likely to report an overall HRQoL below the median. Moreover, in the crude model, participants with MAIS 3 classified injuries and a 'Gradual decrease' pattern were more likely to report problems with mobility, usual activity and pain/discomfort compared with the 'Stable' pattern (see table 3 for details).

\section{DISCUSSION}

The results of this long-term follow-up study revealed three distinct patterns of SA for people who have suffered 


\begin{tabular}{|c|c|c|c|c|c|}
\hline Quality of life & $\begin{array}{l}\text { Total } \\
(n=903)\end{array}$ & $\begin{array}{l}\text { 'Stable' } \\
\text { (n=687) }\end{array}$ & $\begin{array}{l}\text { 'Quick decrease' } \\
(n=137)\end{array}$ & $\begin{array}{l}\text { 'Gradual decrease' } \\
(n=79)\end{array}$ & $\begin{array}{l}P \\
\text { values }\end{array}$ \\
\hline Total & n (\%) & $n(\%)$ & $\mathrm{n}(\%)$ & $\mathrm{n}(\%)$ & \\
\hline Overall quality of life below median (0.796) & $304(33.7)$ & $182(26.5)$ & $67(48.9)$ & $55(69.6)$ & $<0.001$ \\
\hline Problem in mobility & $130(14.4)$ & $68(9.9)$ & $27(19.7)$ & $35(44.3)$ & $<0.001$ \\
\hline Problem in self-care & $42(4.7)$ & $22(3.2)$ & $7(5.1)$ & $13(16.5)$ & $<0.001$ \\
\hline Problem in usual activity & $187(20.7)$ & $102(14.8)$ & $45(32.8)$ & $40(50.6)$ & $<0.001$ \\
\hline Pain/discomfort & $482(53.4)$ & $316(46.0)$ & $101(73.7)$ & $65(82.3)$ & $<0.001$ \\
\hline Anxiety/depression & $279(30.9)$ & $183(26.6)$ & $57(41.6)$ & $39(49.4)$ & $<0.001$ \\
\hline MAIS (1 and 2) & $\mathrm{n}=698$ & $n=579$ & $\mathrm{n}=78$ & $\mathrm{n}=41$ & \\
\hline Overall quality of life below median & $203(29.1)$ & $141(24.4)$ & $36(46.2)$ & $26(63.4)$ & $<0.001$ \\
\hline Problem in mobility & $75(10.7)$ & $47(8.1)$ & $14(17.9)$ & $14(34.1)$ & $<0.001$ \\
\hline Problem in self-care & $24(3.4)$ & $16(2.8)$ & $1(1.3)$ & $7(17.1)$ & $<0.001$ \\
\hline Problem in usual activity & $125(17.9)$ & $83(14.3)$ & $23(29.5)$ & $19(46.3)$ & $<0.001$ \\
\hline Pain/discomfort & 348 (49.9) & $258(44.6)$ & $58(74.4)$ & $32(78.0)$ & $<0.001$ \\
\hline Anxiety/depression & $198(28.4)$ & $147(25.4)$ & $31(39.7)$ & $20(48.8)$ & $<0.001$ \\
\hline MAIS $\geq 3$ & $n=205$ & $n=108$ & $\mathrm{n}=59$ & $\mathrm{n}=38$ & \\
\hline Overall quality of life below median & $101(49.3)$ & $41(38.0)$ & $31(52.5)$ & $29(76.3)$ & $<0.001$ \\
\hline Problem in mobility & $55(26.8)$ & $21(19.4)$ & $13(22.0)$ & $21(55.3)$ & $<0.001$ \\
\hline Problem in self-care & $18(8.8)$ & $6(5.6)$ & $6(10.2)$ & $6(15.8)$ & 0.144 \\
\hline Problem in usual activity & $62(30.2)$ & $19(17.6)$ & $22(37.3)$ & $21(55.3)$ & $<0.001$ \\
\hline Pain/discomfort & $134(65.4)$ & $58(53.7)$ & $43(72.9)$ & $33(86.8)$ & $<0.001$ \\
\hline Anxiety/depression & $81(39.5)$ & $36(33.3)$ & $26(44.1)$ & $19(50.0)$ & 0.136 \\
\hline
\end{tabular}

HRQoL, health-related quality of life; MAIS, Maximum Abbreviated Injury Scale; SA, sickness absence.

an RTI. A majority of the participants followed the 'Stable' pattern (76\%), with a low number of SA days throughout the study period. Participants belonging to the 'Quick decrease' (15\%) and 'Gradual decrease' (9\%) patterns reported a higher mean number of SA days at the beginning of the study period compared with the 'Stable' pattern; however, these three patterns were at the same level of SA days at the third year of follow-up. The findings of three distinct patterns are in line with Galatzer-Levy and colleagues' review ${ }^{41}$ of studies using trajectory modelling in relation to resilience and dysfunction following potential trauma. They found that the most common number of trajectories identified in the studies included in the review was four, however, a delayed onset of psychological reactions to trauma was not found in RTI populations. As in the review, we did not identify a delayed onset trajectory in the current study.

When injury severity was considered, participants with MAIS $\geq 3$ classified injuries initially had a higher number of SA days and a quicker reduction of SA days compared with those with less severe injuries. These findings indicate that serious injuries lead to SA days in proximity to the RTI, but also to a quick reduction of the number of SA days following the injury. Despite these results being in line with previous findings of injury-related factors as a predictor of return to work following RTI, ${ }^{18-21}$ it is important to consider these results as they highlight a limitation of using injury severity as a predictor of longterm sequelae of RTI. Although the MAIS injury severity scale addresses the most severe of multiple injuries, it was designed for prediction of survival and not for determination of long-term sequelae. ${ }^{31}{ }^{32}$ The threat to life can initially be high, although the risk of physical long-term consequences can be low. This may in practice mean that if a person with a high injury severity score survives the initial injury period, he or she might not be as likely to have long-term consequences as someone who has a lower injury severity score but may experience longterm sequelae, for example, whiplash injury. ${ }^{7}$ Moreover, previous findings indicate that biological and psychological factors may have a larger impact on the development of reactions to stress compared with the level of injury severity. ${ }^{41}$

Additionally, the pattern of SA after RTI would have been missed if we had assessed the number of SA days at a specific point in time. Considering the variation of the results in previous studies that have used a single point in time for the evaluation of SA and return to work following RTI, ${ }^{814}$ it is plausible that the previous results are either underestimated or overestimated, depending on the time point of the evaluation. The variation in SA over time also makes the comparison across different studies difficult as 
Table 3 The associations between SA pattern group and low quality of life: logistic regression

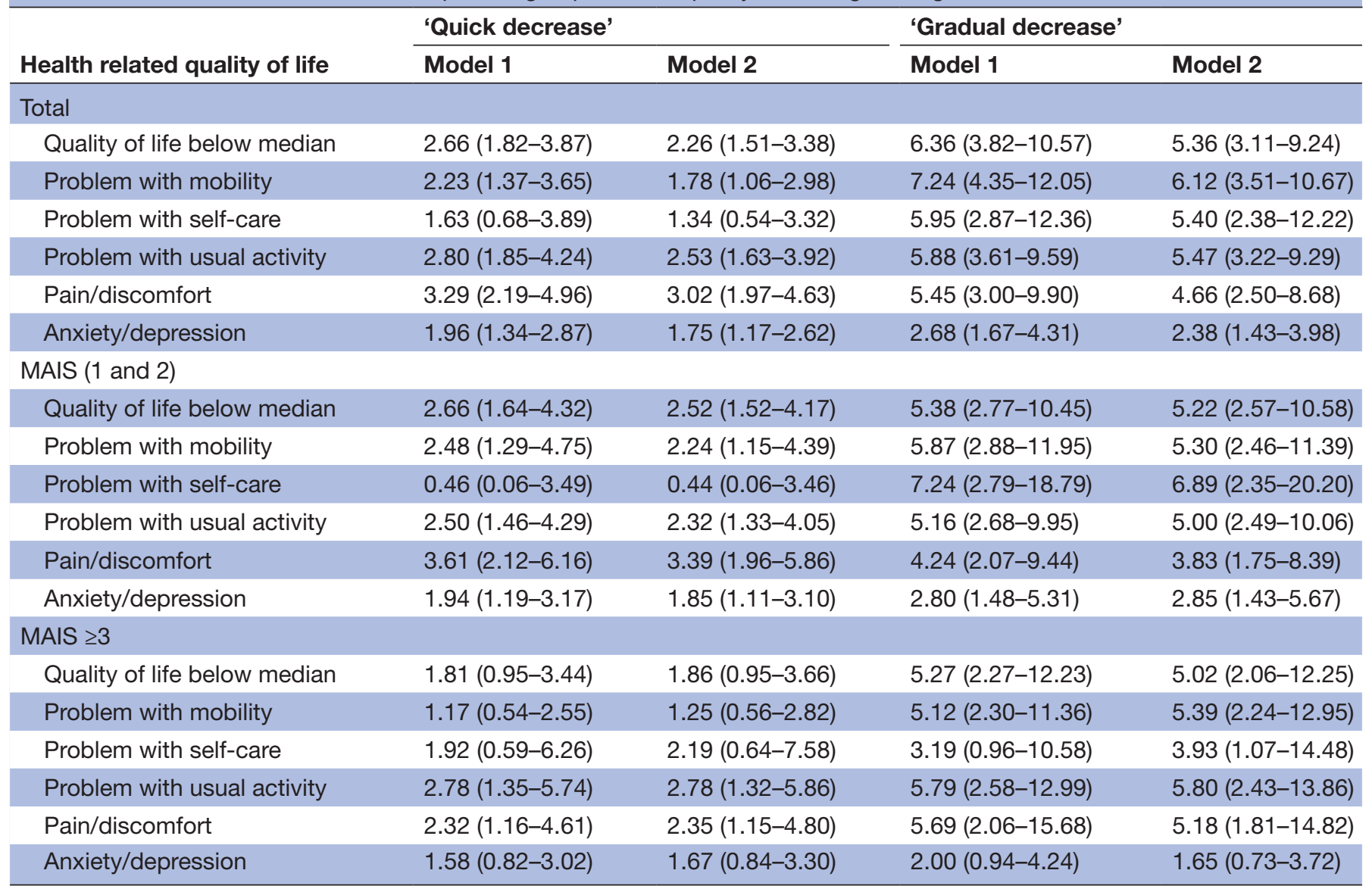

'Stable' pattern was considered as the reference group. *OR and 95\% $\mathrm{Cl}$ were shown in model 1 (crude model) and in model 2 after being adjusted for age, sex, education, sick leave days 1 year prior to injury, time interval between injury and quality of life survey, and if applicable, MAIS.

MAIS, Maximum Abbreviated Injury Scale; SA, sickness absence.

the rate of persons reporting SA might be dependent on the time of the evaluation, independent of injury severity.

Expanding on prior research, we also found higher injury severity and higher number of SA days to have a negative interplay with HRQoL. HRQoL was higher among participants with MAIS 1 and 2 classified injuries compared with participants with MAIS 3+ classified injuries. Participants who initially had a higher number of SA days were also more likely to report low HRQoL, which indicates that participants with a 'Gradual decrease' pattern of SA might be more vulnerable with regard to SA and HRQoL loss after an RTI. Participants in the 'Gradual decrease' pattern suffered more severe injury to a larger extent and were slightly older than those with other SA patterns, which suggested that in addition to injury severity, age could also influence both return to work and HRQoL after an RTI. Proposed explanatory theories and previous research ${ }^{7243}$ are in agreement with this finding as they suggest that older individuals might be more vulnerable due to pre-existing disease or comorbidities compared with younger individuals.

There are both strengths and limitations to this study, which are worth mentioning. The strength of this study is the unique combination of data collection modes, where HRQoL was collected by a self-reported questionnaire and SA and injury data were retrieved from national high-quality registers containing social insurance data for all residents in Sweden, with practically no loss to follow-up. As the Swedish social insurance scheme also covers people on unemployment benefits, there is no attrition; thus, the registers have good validity, which have been evaluated in previous studies. ${ }^{44}$ However, caution should be taken when interpreting the results regarding short-time SA, as SA spells shorter than 14 days are not captured in this study; hence, the magnitude of the problem with SA might be underestimated. The first 14 days of SA are compensated to the individual by the employer (employer-paid sick leave) and are therefore not registered by the Swedish Social Insurance Agency. This has previously been noted as a limitation in studies using Swedish social insurance data. ${ }^{9}$ Considering that there is an increase in the number of studies using self-reported SA as an outcome following injury, the quality of the SA data is important. By using high-quality national register data, biassed results due to differential or non-differential misclassification can be avoided as in our study. 
The results regarding the HRQoL should also be interpreted with caution, as there is a potential power problem due to the low number of participants reporting problems in each domain and stratum. For the comparison of problems in self-care and anxiety/depression for participants with injury severity of MAIS $\geq 3$ the estimated power was less than 0.7 , which is a limitation of the study. It is plausible that people who have the biggest impact on their HRQoL and people with very severe injuries are missing in the current study population due to them declining participation. However, our previous experience of studies involving people who have suffered an RTI is that they are willing to share and participate in research concerning their well-being and health. ${ }^{46}$

Moreover, we were not able to assess HRQoL over several time points; hence, we cannot draw conclusions on the change of QoL over the study period. Although this study presented limitations regarding the HRQoL measure, the results concur with previous findings that there is a negative association between the number of SA days and a lower HRQoL. ${ }^{10-12}$

It should also be noted that the results presented in this study are limited to RTI resulting in emergency care, as only patients who seek medical care at emergency departments are captured in STRADA. Cohorts based on emergency care are naturally biassed towards more severe and moderate cases; hence, there is likely to be an underestimation of the consequences for those with less severe injuries as these do not necessarily require emergency care. Moreover, as this study aimed to increase the limited knowledge regarding the dynamic patterns of SA after an RTI, we did not stratify the analysis by injury type or injured body part, which would be granted for future studies. Thus, a more comprehensive in-depth longitudinal study, considering a patient mix and persons affected by RTI and who have not consulted emergency care, is warranted.

Furthermore, we have not been able to control for the adjustment latitude or attendance requirements at work, which have been shown to affect levels of SA. Low SA can reflect work ability either due to good health or reflect good possibilities to adjust the work to health problems. On the other hand, it could also reflect high sickness attendance, that is, attending work despite feeling unwell, which has been shown to relate to occupational groups whose everyday tasks involve providing care or welfare services, teaching and to occupations in which one cannot be replaced. ${ }^{47}$ Moreover, we have not controlled for occupation or employer factors such as size of workplace/company, job demands or support offered at the workplace, which have been shown to influence SA and return to work rates. ${ }^{48}$

In conclusion, this study highlights the heterogeneity of return to work after an RTI. People with a more severe injury and a slower pace of return to work seem to be more vulnerable with regard to HRQoL loss following RTI. In elaborating on these findings, it is important to view return to work as a dynamic process; this is particularly important with respect to when designing interventions for returning to work following RTI. These interventions should consider both the injury severity and the HRQoL of the person as these variables interplay with return to work. It is not merely in developing interventions that the results from this study should be considered, but also in relation to policies. One such example is in relation to the recent policy change in Sweden, ${ }^{49}$ which defines that employers are required to provide rehabilitation plans for all employees with an expected SA longer that 60 days counted from the first days of absence, independent of cause, with the exception of anticipated return to work with the 60-day period. As the trajectories of SA following RTI are not well studied or known, it is difficult to predict return to work. Hence, the results from this study combined with previous studies can aid as a guidance in the establishment of these rehabilitation plans, with special attention to those with more severe injuries as they seem to be more vulnerable regarding return to work and HRQoL following an RTI.

Contributors RR conceptualised the project and drafted the manuscript. H-YB collected the data. YL performed the statistical analyses. YL, JM, AN, H-YB and $\mathrm{MH}$ reviewed and edited the manuscript. All authors read and approved the final manuscript.

Funding This work was supported by Skyltfonden grant number TRV 2015/85015. Competing interests None declared.

Patient consent for publication Not required.

Ethics approval The Regional Ethical Review Board in Stockholm (case number: 2016/182-31).

Provenance and peer review Not commissioned; externally peer reviewed.

Data availability statement Data files used in the study are securely held by the Swedish Transport Agency, the Swedish Social Insurance Agency, Statistics Sweden and cannot be shared by the authors, but are available via application (see www. transportstyrelsen.se; www.forsakringskassan.se; www.scb.se).

Open access This is an open access article distributed in accordance with the Creative Commons Attribution Non Commercial (CC BY-NC 4.0) license, which permits others to distribute, remix, adapt, build upon this work non-commercially, and license their derivative works on different terms, provided the original work is properly cited, appropriate credit is given, any changes made indicated, and the use is non-commercial. See: http://creativecommons.org/licenses/by-nc/4.0/.

\section{REFERENCES}

1. Peden M. World report on road traffic injury prevention 2004.

2. European Transport Safety Council E. Social and economic consequences of road traffic injury in Europe. Brussels: Council ETS, 2007.

3. Physicians TRACo. Australasian faculty of occupational and environmental medicine position statement on realising the health benefits work. Sydney, 2010.

4. Rueda S, Chambers L, Wilson M, et al. Association of returning to work with better health in working-aged adults: a systematic review. Am J Public Health 2012;102:541-56.

5. Pransky G, Gatchel R, Linton SJ, et al. Improving return to work research. J Occup Rehabil 2005;15:453-7.

6. Gray SE, Hassani-Mahmooei B, Cameron ID, et al. Patterns and predictors of failed and sustained return-to-work in transport injury insurance claimants. J Occup Rehabil 2018;28:740-8.

7. Berecki-Gisolf $\mathrm{J}$, Collie A, McClure R. Work disability after road traffic injury in a mixed population with and without hospitalisation. Accid Anal Prev 2013;51:129-34.

8. Matthews LR. Work potential of road accident survivors with posttraumatic stress disorder. Behav Res Ther 2005;43:475-83. 
9. Styrke J, Stålnacke B-M, Bylund P-O, et al. Neck injury after whiplash trauma in a defined population in northern Sweden long-term sick leave and costs of low productivity. Epidemiology 2014;170.

10. Heron-Delaney M, Warren J, Kenardy JA. Predictors of non-return to work 2 years post-injury in road traffic crash survivors: results from the UQ support study. Injury 2017;48:1120-8.

11. Pélissier $\mathrm{C}$, Fort $\mathrm{E}$, Fontana $\mathrm{L}$, et al. Factors associated with nonreturn to work in the severely injured victims 3 years after a road accident: a prospective study. Accid Anal Prev 2017;106:411-9.

12. Moergeli H, Wittmann L, Schnyder U. Quality of life after traumatic injury: a latent trajectory modeling approach. Psychother Psychosom 2012;81:305-11.

13. Paiva L, Pompeo DA, Ciol MA, et al. Health status and the return to work after traffic accidents. Rev Bras Enferm 2016;69:443-50.

14. Lilley R, Davie G, Ameratunga S, et al. Factors predicting work status 3 months after injury: results from the prospective outcomes of injury study. BMJ Open 2012;2:e000400.

15. Gabbe BJ, Simpson PM, Sutherland AM, et al. Evaluating time points for measuring recovery after major trauma in adults. Ann Surg 2013;257:166-72.

16. Pashaei Sabet F, Norouzi Tabrizi K, Khankeh HR, et al. Road traffic accident victims' experiences of return to normal life: a qualitative study. Iran Red Crescent Med J 2016;18:e29548.

17. Pérez-Núñez R, Pelcastre-Villafuerte $B$, Híjar $M$, et al. A qualitative approach to the intangible cost of road traffic injuries. Int $\mathrm{J}$ Inj Contr Saf Promot 2012;19:69-79.

18. Hours M, Chossegros L, Charnay P, et al. Outcomes one year after a road accident: results from the ESPARR cohort. Accid Anal Prev 2013;50:92-102.

19. Tournier $\mathrm{C}$, Charnay $\mathrm{P}$, Tardy $\mathrm{H}$, et al. A few seconds to have an accident, a long time to recover: consequences for road accident victims from the ESPARR cohort 2 years after the accident. Accid Anal Prev 2014;72:422-32.

20. Fitzharris M, Bowman D, Ludlow K. Factors associated with returnto-work and health outcomes among survivors of road crashes in Victoria. Aust N Z J Public Health 2010;34:153-9.

21. Murgatroyd DF, Harris IA, Tran Y, et al. Predictors of return to work following motor vehicle related orthopaedic trauma. BMC Musculoskelet Disord 2016;17:171.

22. Read KM, Kufera JA, Dischinger PC, et al. Life-altering outcomes after lower extremity injury sustained in motor vehicle crashes. $J$ Trauma 2004;57:815-23.

23. Fort E, Bouffard E, Charnay P, et al. Return to work following road accidents: factors associated with late work resumption. J Rehabil Med 2011;43:283-91.

24. Monárrez-Espino J, Laflamme L, Berg H-Y. Measuring and assessing risk of quality of life loss following a road traffic injury: a proposed methodology for use of a composite score. Accid Anal Prev 2018:115:151-9.

25. Karlsson $\mathrm{H}$, Olsson $\mathrm{H}$, Carneck $\mathrm{A}$. Medelpensioneringsålder och utträdesålder, m.m 2016.

26. Österlund N. MiDAS Sjukpenning och Rehabiliteringspenning Version 1.02 [in English: MiDAS Sikness benefit and rehabilitation compensation. Stockholm: Swedish Social Insurance Agency, 2011.

27. SCB. Longitudinell integrationsdatabas för Sjukförsäkrings- och Arbetsmarknadsstudier (LISA) 1990-2013 2016.

28. Socialförsäkringsbalk. Socialförsäkringsbalk. In: MoHaS A, ed. Stockholm, 2010.
29. Försäkringskassan. Sjukskrivningar 60 dagar eller längre en beskrivning AV sjukskrivna åren 1999-2014 efter kön, ålder, arbetsmarknadsstatus, yrke, sjukskrivningslängd och diagnospanorama, 2015

30. Vägverket. Nytt nationellt informationssystem för skador och olyckor inom HeLa vägtransportsystemet, 2007.

31. States JD. The abbreviated and the comprehensive research injury scales: SAE international, 1969.

32. AAAM. The abbreviated injury scale, 1985 revision. Des Plaines IL, USA, 1985

33. WHOQOL Group. Study protocol for the world Health organization project to develop a quality of life assessment instrument (WHOQOL). Qual Life Res 1993;2:153-9.

34. Wilson IB, Cleary PD. Linking clinical variables with health-related quality of life. A conceptual model of patient outcomes. JAMA 1995;273:59-65.

35. EuroQol Group. EuroQol--a new facility for the measurement of health-related quality of life. Health Policy 1990;16:199-208.

36. Hung M-C, Lu W-S, Chen S-S, et al. Validation of the EQ$5 \mathrm{D}$ in patients with traumatic limb injury. J Occup Rehabil 2015;25:387-93.

37. Öster $\mathrm{C}$, Willebrand $M$, Dyster-Aas J, et al. Validation of the $E Q-5 D$ questionnaire in burn injured adults. Burns 2009;35:723-32.

38. Obradovic M, Lal A, Liedgens $\mathrm{H}$. Validity and responsiveness of EuroQol-5 dimension (EQ-5D) versus short Form-6 dimension (SF-6D) questionnaire in chronic pain. Health Qual Life Outcomes 2013;11:110.

39. Jung T, Wickrama KAS. An introduction to latent class growth analysis and growth mixture modeling. Soc Personal Psychol Compass 2008:2:302-17.

40. Andruff H, Carraro N, Thompson A, et al. Latent class growth modelling: a tutorial. Tutor Quant Methods Psychol 2009;5:11-24.

41. Galatzer-Levy IR, Huang SH, Bonanno GA. Trajectories of resilience and dysfunction following potential trauma: a review and statistical evaluation. Clin Psychol Rev 2018;63:41-55

42. Gopinath B, Harris IA, Nicholas M, et al. A comparison of health outcomes in older versus younger adults following a road traffic crash injury: a cohort study. PLoS One 2015;10:e0122732.

43. Andersen D, Ryb G, Dischinger P, et al. Self-Reported health indicators in the year following a motor vehicle crash: a comparison of younger versus older subjects. Ann Adv Automot Med 2010;54:359-67.

44. Ljungdahl LO, Bjurulf P. The accordance of diagnoses in a computerized sick-leave register with doctor's certificates and medical records. Scand J Soc Med 1991;19:148-53.

45. Ludvigsson JF, Almqvist C, Bonamy A-KE, et al. Registers of the Swedish total population and their use in medical research. Eur $J$ Epidemiol 2016;31:125-36.

46. Hasselberg M, Kirsebom M, Bäckström J, et al. I did NOT feel like this at all before the accident : do men and women report different health and life consequences of a road traffic injury? Injury Prevention 2018.

47. Aronsson G, Gustafsson K, Dallner M. Sick but yet at work. An empirical study of sickness presenteeism. J Epidemiol Community Health 2000;54:502-9.

48. Kristman VL, Shaw WS, Boot CRL, et al. Researching complex and multi-level workplace factors affecting disability and prolonged sickness absence. J Occup Rehabil 2016;26:399-416.

49. Socialförsäkringsbalken. Arbetsgivarens skyldigheter 2018. 